GU J Sci, Part C, 6(4): 787-802 (2018)

Gazi Üniversitesi
Fen Bilimleri Dergisi
PART C: TASARIM VE TEKNOLOJI
http://dergipark.gov.tr/gujsc

\title{
Polipropilen/Polianilin Kompozit Filmlerin Dielektrik Özelliklerinin Yapay Sinir Ağları Modeli İle Tahmini
}

\author{
Önder EYECIOĞLU ${ }^{1, *}$ Mehmet KILIÇ², Zeynep GÜVEN ÖZDEMIR ${ }^{2}$ \\ ${ }^{1}$ Nişantaşı Üniversitesi, Mühendislik Mimarlık Fakültesi, Bilgisayar Mühendisliği Bölümü, 34485, Sarlyer/ISTANBUL \\ ${ }^{2}$ Yıldız Teknik Üniversitesi, Fen Edebiyat Fakültesi, Fizik Bölümü, 34220, Esenler/ISTANBUL
}

$\ddot{O ̈ z}$

\section{Makale Bilgisi \\ Basvuru: 24/02/2018 \\ Düzeltme: 26/08/2018 \\ Kabul: $14 / 10 / 2018$}

\section{Anahtar Kelimeler}

Yapay Sinir Ağlart Dielektrik Spektroskopisi Polipropilen Polianilin

\section{Keywords}

Artificial Neural Networks Dielectric Spectroscopy Polypropylene

Polyaniline

\begin{abstract}
Bu çalışmada, polipropilen (PP) polimerinin frekansa bağlı kompleks dielektrik fonksiyonunun gerçek ve sanal bileşenlerinin, kütlece $\% 0,3,0,4,0,6$ ve 0,7 polianilin (PANI) katkısına bağlı olarak değişimi dielektrik spektroskopisi yöntemiyle incelenmiştir. Dielektrik ölçümler, $100 \mathrm{~Hz}$ ile $15 \mathrm{MHz}$ arasında değişen frekans aralığında oda sıcaklığında empedans analizör yardımıyla gerçekleştirilmiştir. Deneysel sonuçlar, PANI katkısıyla PP'nin dielektrik parametrelerinin lineer olmayan bir değişim sergilediğini göstermiștir. Bu bağlamda öncelikle, PP/PANI kompozitlerin kompleks dielektrik fonksiyonlarının gerçek ve sanal bileşenlerinin frekansa bağlılığının Yapay Sinir Ağları (YSA) modeli ile tahmin edilebileceği gösterilmiştir. Ardından, deneysel olarak hazırlanmamış farklı PP/PANI kompozitler için YSA modeliyle kütlece farklı PANI katkı yüzdeleri için (\% 0,1, 0,2, 0,5, 0,8 ve 1$)$, kompleks dielektrik fonksiyonun gerçek ve sanal bileşenlerin frekansa bağlı değişimleri hesaplanmıştır. YSA modeli ile elde edilen sonuçlar, kompleks dielektrik fonksiyonlarının gerçek ve sanal bileşenlerinin artan PANI katkısıyla lineer olmayan değişimiyle uyumlu olarak bulunmuştur. Böylelikle, kondansatör gibi çeşitli dielektrik uygulamalar için istenilen dielektrik parametrelere sahip PP/PANI kompozitlerin üretiminde uygun kütlece PP ve PANI yüzdeleri öngörülebilir.
\end{abstract}

\section{Prediction of Dielectric Properties of Polypropylene/Polyaniline Composite Films By Artificial Neural Networks Model}

\begin{abstract}
In this study, the change of the frequency dependence of the real and imaginary components of the complex dielectric function of the polypropylene (PP) polymer depending on the addition of $0.3 \%, 0.4 \%, 0.6 \%$ and $0.7 \%$ polyaniline (PANI) was investigated by using dielectric spectroscopy method. Dielectric measurements were performed at room temperature in the frequency range of $100 \mathrm{~Hz}$ to $15 \mathrm{MHz}$ by impedance analyzer. Experimental results have shown that the dielectric parameters of PP exhibit non-linear variation with the PANI contribution. In this context, firstly, it has been shown that the frequency dependence of real and virtual components of complex dielectric functions of PP / PANI composites can be estimated with Artificial Neural Network (ANN) model. Then, the frequency dependences of the real and imaginary components of the complex dielectric function of the PP/PANI composites with different PANI additive concentrations $(0.1,0.2,0.5,0.8$, and $1.0 \%)$, which were not prepared experimentally, were calculated by using ANN method. The results obtained with the YSA model were also found to be consistent with the nonlinear variation of the real and imaginary components of complex dielectric function with increasing PANI doping. Hence, suitable PP and PANI mass percentages can be predicted in the production of PP/PANI composites with desired dielectric parameters for various dielectric applications such as capacitor.
\end{abstract}

\section{GİRIŞ (INTRODUCTION)}

Polipropilen (PP) ve düşük yoğunluklu polietilen (DYPE) gibi yalıtkan karakter gösteren polimerler hem düşük maliyetleri hem de iyi elektriksel, mekanik ve optik özelliklere sahip olmalarından dolayı, optoelektronik uygulamalarda yaygın olarak kullanılmaktadırlar [1-3]. Bununla birlikte, son otuz yılda elektrik, mekanik ve ısısal özelliklerinin kullanılacakları uygulama alanına yönelik olarak ayarlanabildiği yeni nesil polimer kompozit malzemeler, saf polimerler (katkısız) malzemelerin yerini büyük ölçüde almıştır. Özellikle iletken polimer kompozitler ayarlanabilir elektriksel özellikleri, hafif oluşları, korozyona 
dayanımları, esnek ve işlenebilir olmaları nedeniyle ön plana çıkmaktadır [4]. Yüksek elektriksel iletkenliğe sahip olan polianilin (PANI), gerek çevresel koşullara karşı gösterdiği kararlılığı gerekse de iyi elektriksel ve elektrokimyasal özellikleri sebebiyle; organik elektronikte fotokromik aygıt uygulamalarında, organik alan etkili transistörlerde, kapasitör ve süper kapasitör uygulamalarında [5, 6], polimer tabanlı 1ş1k diyodunda [7], kimyasal ve biyolojik sensör [4, 8] uygulamalarında kullanılmaktadırlar. Ayrıca, PANI'nin elektrokimyasal katalizör [6,9] ve metallerde korozyon önleyici $[7,10]$, olarak kullanıldığı uygulamalar da mevcuttur. Diğer taraftan PANI'nin plastiklerle kıyaslandığında mekaniksel dayanıklı1ığı oldukça zayıftır [11]. Mekanik dayanıklılı̆̆ın artırılması, istenilen elektriksel özellikleri elde etmek amacıyla eldesi PANI içerikli kompozit malzemeler bilim insanları tarafından yoğun olarak çalışılmaktadır [12-14]. Ancak, istenilen özelliklere sahip malzeme elde etmede hazırlanması ve test edilmesi gereken polimer kompozit numune sayısı oldukça fazla olduğundan, deneysel çalışmalar çoğu zaman hem süre hem de maliyet bakımından yapılabilir olamamaktadır. Malzeme ve deneysel parametreleri hesaba katan bir modelin nümerik hesap, benzetim veya tahmin metodu yardımıyla hiç üretilmemiş olan numuneler için olası ve güvenilir sonuçlar üretmesi, yukarıda bahsedilen deneysel dezavantajları aşmanın önemli bir yoludur.

Bir tahmin metodu olarak önerilen yapay sinir ağları (YSA), bir eğitim setinden (örnek; bir deneysel çalışmanın başlangıç parametreleri ve sonuç değerleri) çözümü öğrenerek, alternatif bir hesaplama biçimi sunar. Diğer bir deyişle, YSA basit bir şekilde insan beyninin (veya biyolojik sinir sisteminin) çalışma şeklini taklit eder [15].

YSA tekniği, günümüzde birçok alanda yaygın bir şekilde kullanılmaktadır. Özellikle YSA metodunun kullanım alanları arasında örüntü tanıma, sınıflandırma, finansal ve ekonomik tahmin yürütme, optimizasyon, regresyon, fonksiyon benzetimi, radyo frekans ve mikrodalga ölçümleri, çeşitli katı ve sıvi malzeme ve bileşiklerin dielektrik parametrelerinin tahmini gibi uygulamalar sayılabilir [15-19]. YSA modellemeleri hem işlem süresini hem de analitik karmaşıklı̆̆ azaltmak suretiyle önemli avantaj sağlarlar. Bilindiği üzere, geleneksel ve geleneksel olmayan istatistiksel regrasyon yöntemlerine kıyasla YSA modeli doğruya daha yakın tahmin yapabilmektedir. Ayrıca, YSA modellemelerinin diğer regresyon tekniklerine olan üstünlügüü, problemin boyutsallığg (dimensionality) ve/veya lineer olmaması (non-linearity) arttıkça artmaktadır [20,21]. Çoğu durumda YSA, öğrenme aşaması sırasında ağ boyunca akan dış veya iç bilgilere dayanarak yapısını değiştiren uyarlamalı bir sistem olarak çalışır. Doğrusal olmayan istatistiki veri modelleme aracı olan YSA, girdiler ve çıktılar arasındaki karmaşık ilişkileri modellemek için kullanılabilir ve gözlemden öğrenerek soyutlama yoluyla genellemek için eğitilebilir. Bu nedenle özellikle 2000'li yılların başından itibaren elektromanyetizmadaki çeşitli problemlerin analizinde YSA modelleri etkin olarak kullanılmaya başlanmıştır [22]. Son yıllarda yalıtkan malzemelerin dielektrik parametrelerinin belirlenmesinde YSA yönteminin kullanımı yaygınlaşmaktadır. Örneğin; İnal ve Aras'ın yaptıkları bir çalışmada [23], yalıtkan bir malzeme olan polyesterin sıcaklık ve frekans parametrelerine bağlı olarak dielektrik sabiti ve kayıp faktörü gibi dielektrik özelliklerinin belirlenmesinde YSA yöntemi kullanılmıştır. Yine başka bir çalışmada, [24] Schweitzer ve Morris, bileşiklerin dielektrik sabitlerini deney yapmadan belirleyebilmek için, 497 bileșiğin elektrik dipol momenti, polarize edilebilirlilik, hidrojen bağlama kabiliyetleri gibi kimyasal özelliklerini literatürden edinmiş ve bu tanımlayıcıların dielektrik sabit ile arasındaki ilişkiyi kuracak modeller üretmişlerdir. YSA aracılığıyla bu modeller kullanılarak bileşiklerin dielelektrik sabitlerinin tahminlerini düşük hata oranlarında yapılabilmişlerdir. 2007 yılında Yangjeh ise, farklı oranlarda karıştırılarak elde edilmiş üçlü sıvı karışımlarının farklı sıcaklıklarda ve bileşim oranlarında dielektrik sabitlerinin tahmininde YSA modellemesini kullanmıştır. Araştırma sonuçları, düzgün olarak seçilmiş ve eğitilmiş nöral ağın, dielektrik sabitinin terkip ve sıcaklığa olan lineer olmayan bağımlılığını oldukça iyi bir şekilde tahmin edebileceğini göstermiştir [25]. 2007 yılında Scott ve arkadaşları çeşitli seramik malzemelerin hem iyonik hem de dielektrik özelliklerinin tahmininde YSA modelini kullanmışlardır. Sonuçlar, YSA modellemelerinin, ilgili seramik malzemelerin telekomünikasyon ve enerji üretim uygulamalarında kullanım için uygun materyallerin geliştirilmesinde kullanılabilecek doğrulukta tahminler üretebildiğini göstermiştir [26]. Benzer şekilde, Jurado ve arkadaşları 2009 yılında yaptıkları bir çalışmada, malzemelerin dielektrik sabitini boş uzay (free space) ölçümlerinden elde edilen yansıma katsayısından türetebilmek için Yapay Sinir Ağlarının (YSA) kullanılmasını önermişlerdir [27].

YSA modelinin yukarıda da kısaca özetlenen bilimsel literatürde dielektrik parametre öngörüsündeki başarısına istinaden, bu çalışmada dielektrik spektroskopi tekniği ile dielektrik parametreleri (frekansa bağlı kompleks dielektrik fonksiyonlarının gerçek ve sanal bileşenleri) deneysel olarak belirlenen saf ve 
kütlece farklı oranlarda $(\% 0,3 ; \% 0,4 ; \% 0,6 ; \% 0,7)$ PANI katk1lı PP kompozit filmlerin diğer ara oranlardaki $(\% 0,1 ; \% 0,2 ; \% 0,5 ; \% 0,8 ; \% 1,0)$ dielektrik parametrelerinin tahmini YSA yöntemi ile yapılacaktır. Bu çalışma sonucunda, kütlece değişik oranlarda PP ve PANI içeren kompozitlerin çeşitli dielektrik uygulamalarda kullanılmak üzere dielektrik parametreleri deney yapmadan yüksek doğrulukla tahmin edilebilecektir.

\section{MALZEMELER ve YÖNTEM (MATERIALS AND METHOD)}

\subsection{Malzemeler ve Kompozitlerin Hazırlanışı (Materials and Preparation of The Composites)}

$\mathrm{Bu}$ çalışmada kullanılan polipropilen (erime sıcaklığı: $165{ }^{\circ} \mathrm{C}$ ve yoğunluğu: $0,905 \mathrm{~g} / \mathrm{cm}^{3}$ ) PETKİM Petrokimya Holding A.Ş'den ve PANI (emeraldine base, average Mw 5000, Üretim No: 556459) SigmaAldrich firmasından satın alınmıştır.



Şekil 1. PP/PANI kompozit filmlerin üretim aşamalarının temsili gösterimi.

Granül halindeki PP, ögütücü yardımıyla toz haline getirilerek kütlece $\% 0,3,0,4,0,6$ ve 0,7 oranlarında toz halindeki PANI ile mekanik olarak birbirlerine karıştırılmıştır. Hazırlanan bu karışımlar, çapı 2,4 cm olan dairesel kalıpların içerisine konularak 20 dakika süresince $165^{\circ} \mathrm{C}$ sıcaklıkta ön 1sıtma işlemine tabii tutulmuştur Daha sonra kalıp içerisinde eriyik halde bulunan bu karışımlar, aynı sıcaklıkta $15 \mathrm{MPa}$ basınç altında hidrolik basınçlı preste yaklaşık 10 dakika bekletildikten sonra presten çıkarılıp aniden su içerisinde soğutularak film formunda kompozit numuneler elde edilmiştir (Bakınız Şekil 1).

Sicak pres tekniği ile üretilen numunelerin kalınlıkları 71-100 $\mu \mathrm{m}$ aralığında değişmektedir. Ayrıca, elde edilen kompozit numunelerde PANI'nin film içine homojen olarak dağıldığı gözlenmiştir.

\subsection{Dielektrik Spektroskopisi ve Dielektrik Ölçümler (Dielectric Spectroscopy and Dielectric Measurements)}

Dielektrik spektroskopisi, dielektrik bir malzemenin alternatif akıma (a.c.) verdiği yanıt yardımıyla, açısal frekansa bağlı olarak kompleks dielektrik fonksiyonunun gerçek ve sanal bileşenlerinin belirlenmesini sağlayan bir ölçüm tekniğidir. Dielektrik analiz sayesinde, malzemenin elektriksel geçirgenliği açısal frekansa bağlı kompleks bir dielektrik fonksiyon (elektriksel geçirgenlik, $\varepsilon^{*}(\omega)$ ) olarak elde edilir [28]. dielektrik fonksiyonun açısal frekansa $(\omega)$ bağl1lığı ise,

$$
\varepsilon^{*}(\omega)=\varepsilon^{\prime}(\omega)+i \varepsilon^{\prime \prime}(\omega)
$$


bağıntısı ile verilir. Burada $\varepsilon^{\prime}(\omega)$ ve $\varepsilon^{\prime \prime}(\omega)$ sırası ile kompleks dielektrik fonksiyonun gerçek ve sanal kısımlarına karşı1ık gelmektedir. Dielektrik fonksiyonun gerçek kısmı malzemenin kutuplanabilmesinin veya yük depolayabilmesinin ölçüsünü temsil ederken; sanal bileşeni ise iyonik iletim ya da kutuplanmadan kaynaklanan enerji kaybını temsil eder [28].

Tüm numunelerin frekansa bağlı dielektrik ölçümleri, oda sicaklığında HP 4194A Empedans Analizör sistemi yardımıyla $100 \mathrm{~Hz}-15 \mathrm{MHz}$ frekans aralığında gerçekleştirilmiş̦tir. Veriler GPIB kablosuyla bilgisayara aktarılmış ve aynı anda bilgisayar tarafından kaydedilmiştir. Kalın film formundaki örnekler dairesel şekilli, yüzey alanları $3.14 \mathrm{~cm}^{2}$ olan iki altın elektrot arasına yerleştirilmiş ve ölçümler için geleneksel iki prob tekniği uygulanmıştır. Tüm dielektrik ölçümler için genel hata \% 2,5 civarında iken; rms genliği yaklaşık $500 \mathrm{mV}$ olarak seçilmiştir.

\subsection{Yapay Sinir Ağları (YSA) Modeli (Artificial Neural Networks (ANN) Model)}

Yapay Sinir Ağları modeli, ilgilenilen bir olayı tarif eden, bağımlı ve bağımsız parametreler arasındaki doğrusal olmayan ilişkileri tahmin etmek için kullanılan bir yöntemdir. YSA, bağımsız parametreleri içeren örneklemelerden faydalanarak öğrenme faaliyeti gerçekleştirip, uyarlamalı olarak karar verebilen ve bağımlı değişken üzerinde tahmin yapabilir. Bir YSA modeli, bağlantılı düğümleri (nöron) ve bunların bağlantılarını (ağ) içeren matematiksel bir modeldir. YSA'nın anahtar kavramı olan nöronlar, katmanlar halinde kümelenmiş ön tanımlı hesaplama birimleridir. Nöronlar, üç katman halinde bir araya gelerek bir ağ oluştururlar. Bu katmanlar girdi katmanı, ara katmanlar (gizli katmanlar) ve çıktı katmanıdır (Bakınız Şekil 2).

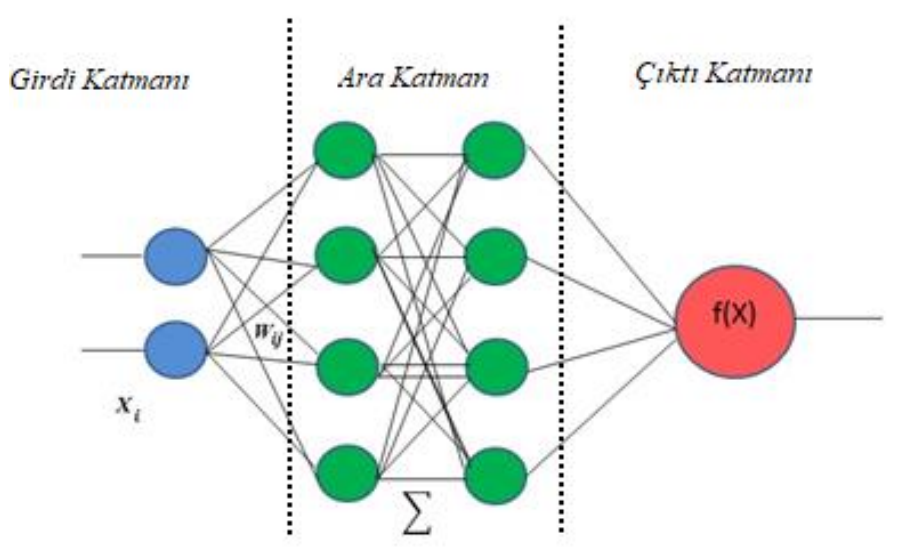

Şekil 2. YSA Katman yapısı.

Bir nöron, çok sayıda giriş parametresinden, girişlerin bağlantı kuvvetinden (ağırlıklar: $w_{i j}$ ), ağırlıklı toplam girişi olarak tanımlanan toplama fonksiyonundan, aktivasyon fonksiyonundan ve çıktılardan oluşur (Bakınız Şekil 3). Net girdiler, i. nöronun, j. nörona göre ağırlıklarına $\left(w_{i j}\right)$ bağlı olarak toplama fonksiyonu ile hesaplanır.

$$
\text { net }_{i}=\sum_{j=1}^{N} w_{i j} x_{j}+b\left(x_{j}: j . \text { nöron çıktı dizisi, } b \text { : bias }\right)
$$




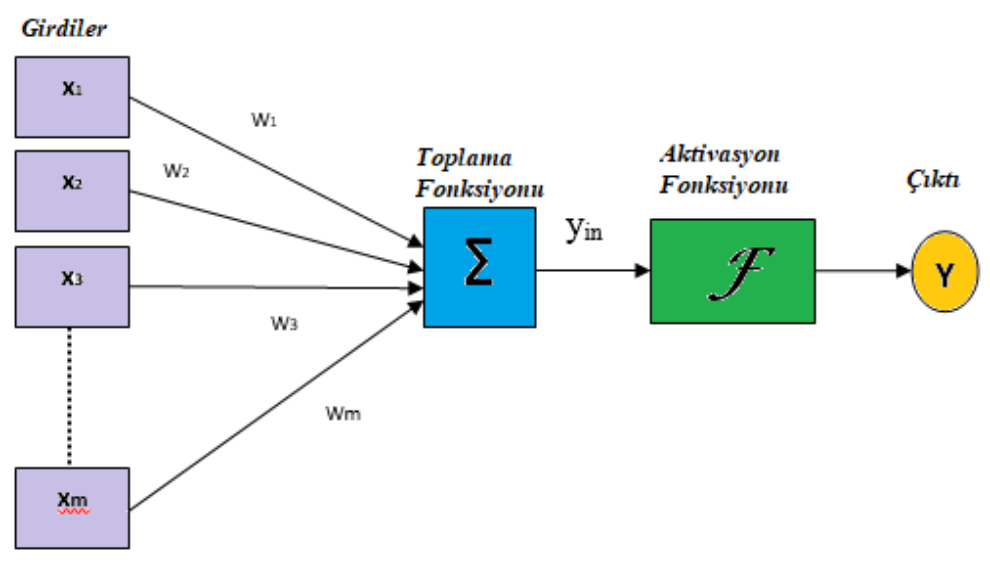

Şekil 3. YSA Nöron yapıst.

YSA’nın işlenmesi iki aşamadan oluşmaktadır. Bu aşamalar, eğitim (training) ve test aşamalarıdır. Bu çalışmada, PP/PANI kompozitlerinde dielektrik fonksiyonlarının, PANI katkısına ve ölçüm yapılan aralıktaki frekans değerlerine bağlılığı doğrusal olmadığından (non-linear) sinir ağları modeli için çok katmanlı ileri beslemeli sinir ağları (MLFF) eğitim modeli kullanılmıştır [29, 30]. Girdi ağırlıklarının güncellenmesi Geri Yayınım (Back Probagation-BB) algoritması [31, 32] ile sağlanmış olup; girdi parametrelerinin ağırlıkları $\left(w_{i j}\right)$, Levenberg-Marquard (LM) algoritması kullanılarak hesaplanmıştır [33, 34]. LM algoritması, lineer olmayan problemlerin kesin çözümleri için, en küçük kareler yöntemleri kullanan çok yaygın iteratif bir yöntemdir. PP/PANI kompozitleri, uygulanan elektriksel frekansa bağlı olarak değişen dinamik yapıda kompleks dielektrik fonksiyonlara sahiptir. Bu çalışmada da, dinamik sistemlerin modellenmesinde etkin bir eğitim yöntemi olan LM algoritması kullanılmıştır. Eğitim aşamasında, parametrelerin ağrılıklarının güncellenmesi [35],

$$
\Delta w=\left[J^{T} J+\mu I\right]^{-1} J^{T} e
$$

bağıntısı ile yapılır. Burada, $w$, ağırlık vektörü, $J$, Jacobien matrisi, $\mu$, ayarlanabilir öğrenme oranı, $I$, birim matris ve $e$, parametrelerin, gerçek değerleri ile tahmin edilen değerlerin aralarındaki mutlak farktan elde edilen hata vektörüdür.

$$
J=\left[\begin{array}{cccc}
\frac{\partial e_{11}}{\partial w_{1}} & \frac{\partial e_{11}}{\partial w_{2}} & \cdots & \frac{\partial e_{11}}{\partial w_{N}} \\
\frac{\partial e_{21}}{\partial w_{1}} & \frac{\partial e_{21}}{\partial w_{2}} & \cdots & \frac{\partial e_{21}}{\partial w_{N}} \\
\cdots & & \\
\frac{\partial e_{p n}}{\partial w_{1}} & \frac{\partial e_{p n}}{\partial w_{2}} & \cdots & \frac{\partial e_{p n}}{\partial w_{N}}
\end{array}\right]
$$

$\mu$, değeri yaklaşık olarak, 0,01 mertebesindedir. Bu değerin büyük olması durumunda, yöntem dereceli alçalma (gradient descent-GD) metoduna dönüşür. Bu yöntem ile bias $(b)$ değerleri de hesaplanır.

YSA yapısında bulunan aktivasyon fonksiyonu ise, ağırlıklı girdilere uygulanarak, çıktıları hesaplayan matematiksel bir fonksiyondur. Sigmoidal aktivasyon fonksiyonu ile hesaplanan i. nöronun çıtısı Denklem (2.4)'deki gibidir. 


$$
\mathrm{out}_{i}=f\left(\mathrm{Net}_{i}\right)=\frac{1}{1+e^{\left(-a \mathrm{Net}_{i}\right)}}
$$

Burada, $a$, yarı-doğrusal bölgenin eğimini kontrol etmek için kullanılan bir sabittir.

Çalışmada uygulanan ağ modelinin performans metrikleri, belirleme katsayısı $(R)$, kare ortalama karekök ( $R M S E)$ ve ortalama kare hata ( $M S E$ ) olarak belirlenmiştir;

$$
\begin{aligned}
& R=\left(\frac{\sum_{i=1}^{N}\left(y_{i}-\bar{y}_{i}\right)\left(x_{i}-\bar{x}_{i}\right)}{\sqrt{\sum_{i=1}^{N}\left(y_{i}-\bar{y}_{i}\right)^{2} \sum_{i=1}^{N}\left(x-\bar{x}_{i}\right)^{2}}}\right) \\
& R M S E=\sqrt{\frac{1}{N} \sum \frac{\left(y_{i}-x_{i}\right)^{2}}{x_{i}}} \\
& M S E=\frac{1}{N} \sum\left(y_{i}-\hat{x}_{i}\right)^{2}
\end{aligned}
$$

Denklem (2.6), (2.7) ve (2.8)'de yer alan $y_{i}$ ve $x_{i}$ sirasılyla tahmin edilen ve ise gerçek değerleri temsil eder.

YSA modeli, MATLAB Neural Network Toolbax ortamında tasarlanmış ve gerçekleştirilmiştir. Eğitim algoritması olarak Levenberg-Marquardt backpropagation algoritması kullanılmıştır. Eğitim süreci 1000 iterasyon süresince uygulanmıştır. Modelin doğrulanması, 10 katlı çapraz doğrulama yöntemi kullanılarak yapılmıştır. YSA eğitim aşaması için gerekli olan veri seti, polar malzemelerin elektriksel özelliklerinin tanımlanmasında kullanılan dielektrik spektroskopisi yöntemi ile elde edilmiştir.

\section{SONUÇLAR VE TARTIŞMA (RESULTS AND DISCUSSION)}

Saf PP ve kütlece \% 0,3, 0,4, 0,6 ve 0,7 PANI katkılandırılmış PP/PANI kompozitlerin kompleks dielektrik fonksiyonlarının gerçek ve sanal kısımlarının frekansla değişimlerine ait deneysel veriler sırasıyla Şekil 4(a) ve (b)'de verildiği gibidir. Özellikle saf PP için dielektrik sabitinin geniş bir frekans aralı̆̆ında gözlenen frekanstan bağımsız davranışı bilimsel literatürdeki diğer araştırmacıların çalışma sonuçları ile uyumludur [36, 37]. Genel olarak, $\varepsilon^{\prime}$ 'nün frekansla değişimi geniş bir frekans aralığında neredeyse frekanstan bağımsız iken; yüksek frekanslarsa $\varepsilon^{\prime}$ değerlerinde ani bir düşüş gözlenmiştir. $\varepsilon^{\prime}$ 'nün frekansa bağlı bu genel davranışı, PANI katkılı PP kompozitler için de geçerlidir. Ayrıca, frekanstan bağımsız ilgili $\varepsilon^{\prime}$ değerleri, malzemenin statik dielektrik sabiti olarak yorumlanabilir. Şekil 4(a)'dan da görüleceği üzere, PANI katkı yüzdesi arttıkça statik dielektrik sabitinin önce azaldığı, sonra arttığı ve son olarak tekrar azalmaktadır. En düşük dielektrik sabiti ise \% 0,3 PANI katkısında elde edilmiştir. Diğer taraftan, Şekil 4(b)'de gösterildiği gibi, saf PP de dâhil olmak üzere tüm PP/PANI kompozitlerin yaklaşık $10^{5} \mathrm{~Hz}$ 'e kadar hepsi frekanstan bağımsız ve şiddetçe oldukça düşük dielektrik kayıba $\left(\varepsilon^{\prime \prime}\right)$ sahiptiler. Bununla birlikte, $\varepsilon^{\prime \prime}=f(\omega)$ eğrileri numunelerin yüksek frekans bölgesinde bir relaksasyon tepesine sahip olduğunu göstermektedir. Relaksasyon tepesinin gözlendiği frekans ise artan PANI katkısıyla birlikte, önce yüksek daha sonra düşük ve son olarak yüksek frekanslara kaymıştır. 

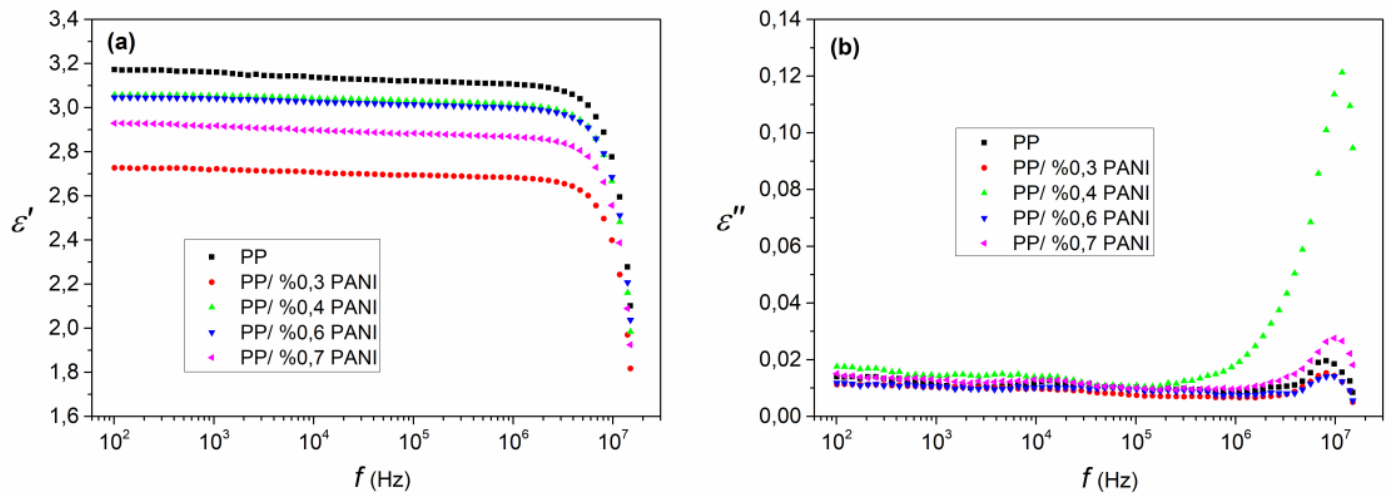

Şekil 4. Saf PP ve PP/PANI kompozitlerin kompleks dielektrik fonksiyonlarının (a) gerçek ve (b) sanal kısımlarının frekansla değişimleri.

Saf PP ve PP/PANI kompozitlerin frekansa bağlı dielektrik özelliklerini ( $\varepsilon^{\prime}$ ve $\varepsilon^{\prime \prime}$ ) YSA metodu ile elde edebilmek için, Şekil 4'de verilen deneysel veriler, YSA metodunun eğitimi için kullanılmıştır. YSA eğitimi için 334 adet veri seti kullanılmıştır. Her bir veri seti dört bağımlı ve bağımsız parametre içermektedir. Bu veri setlerinde $\varepsilon^{\prime}$ ve $\varepsilon^{\prime \prime}$ bağımlı değişkenlerinin, a.c. sinyalin frekansına $(f(H z))$ ve PANI konsantrasyonuna $(c(\%))$ bağlı değişimleri bulunmaktadır (Bakınız Tablo 1). Girdi verisinde ise 1336 adet veri bulunmaktadır. Bu veriler rastgele olarak ikiye ayrılmıştır. İlgili verilerin \%80’i eğitim verisi olarak, \% 20'si ise test verisi olarak kullanılmıştır.

Tablo 1. YSA ĕgitim girdi verileri

\begin{tabular}{|c|c|c|}
\hline Parametre & Aralık & Ortalama \\
\hline$c(\%)$ & $0 ; 0,3 ; 0,4 ; 0,6 ; 0,7$ & 0,399 \\
\hline$f(H z)$ & $100,706-1,500 \times 10^{7}$ & $1,484 \times 10^{6}$ \\
\hline$\varepsilon^{\prime}(\omega)$ & $1,817-3,172$ & 2,909 \\
\hline$\varepsilon^{\prime \prime}(\omega)$ & $0,01-0,121$ & 0,014 \\
\hline
\end{tabular}

1000 iterasyon kullanılarak gerçekleştirilen eğitim süreçlerine ait çıktılar Şekil 5 ve Şekil 6' da verilmiştir. 


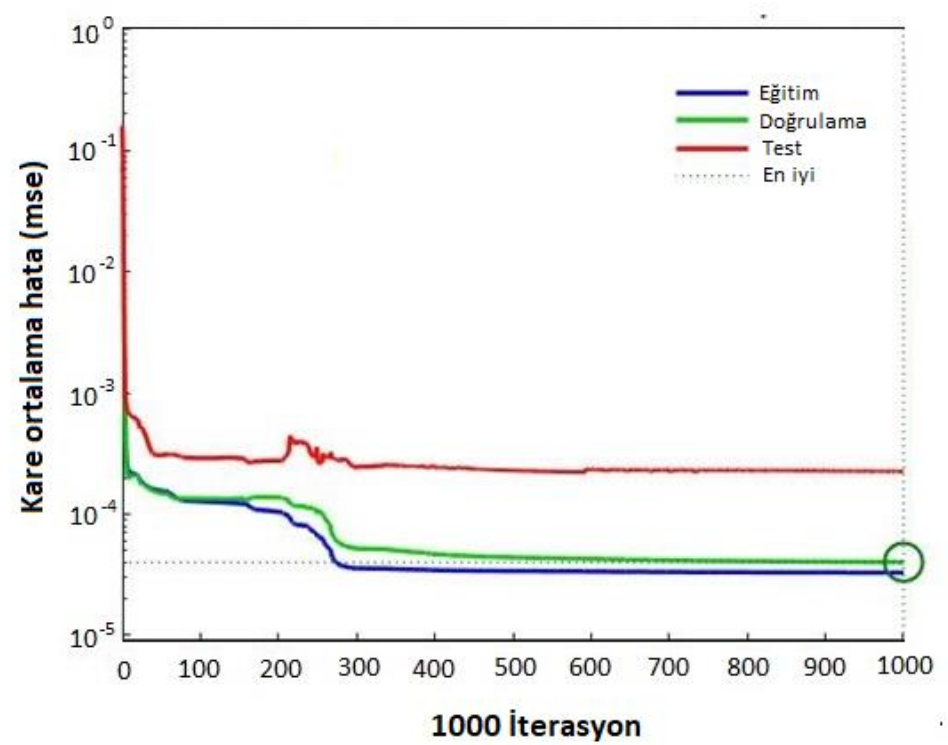

Şekil 5. Eğitim doğrulama ve test süreçlerinde kare ortalama hata değerinin iterasyon adımına bağlı değişimleri

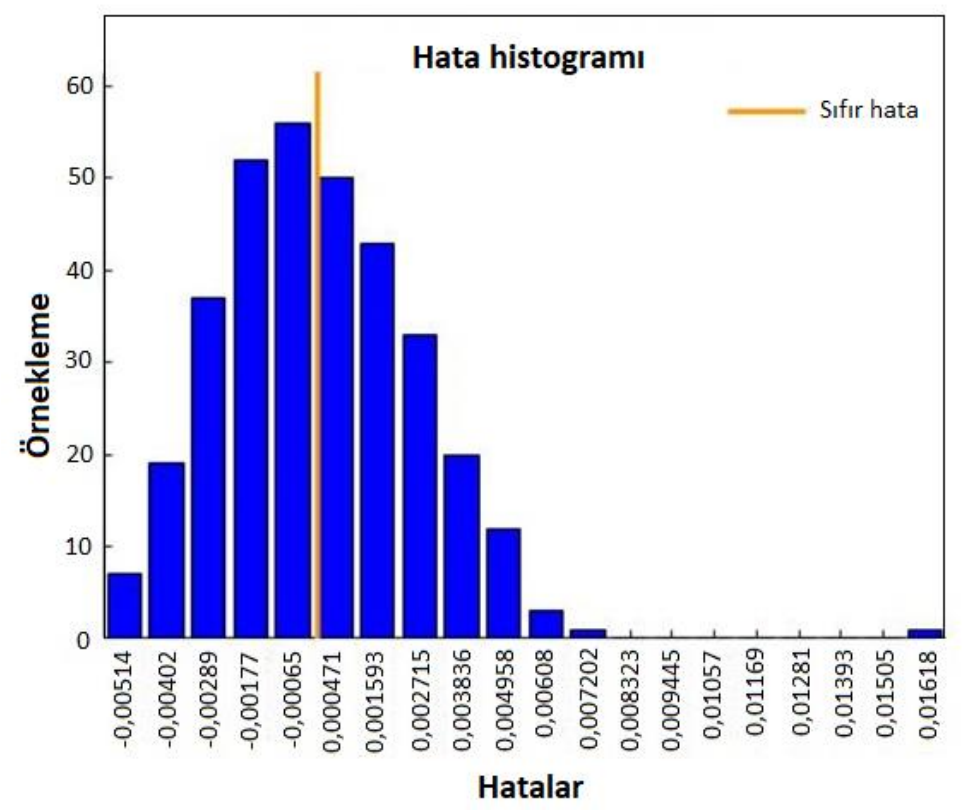

Şekil 6. Hata histogram grafiği.

Modelin doğruluğu, 10 katlı çapraz doğrulama yöntemi ile kontrol edilmiştir. Her bir doğrulamaya ait $\varepsilon^{\prime}(\omega)$ ve $\varepsilon^{\prime \prime}(\omega)$ değişkenlerinin belirleme katsayıları $(R)$ Tablo 2 de verilmiştir. 
Tablo 2. YSA modelinin 10 katlı çapraz doğrulamasına ait belirleme katsayısı değerleri

\begin{tabular}{|c|c|c|}
\hline$k$ & \multicolumn{2}{|c|}{$R$} \\
\hline$i ; i=1: i=10$ & $\varepsilon^{\prime}(\omega)$ & $\varepsilon^{\prime \prime}(\omega)$ \\
\hline 1 & 0,999 & 0,994 \\
\hline 2 & 0,998 & 0,994 \\
\hline 3 & 0,999 & 0,984 \\
\hline 4 & 0,999 & 0,993 \\
\hline 5 & 0,998 & 0,991 \\
\hline 6 & 0,999 & 0,993 \\
\hline 7 & 0,998 & 0,994 \\
\hline 8 & 0,998 & 0,993 \\
\hline 9 & 0,999 & 0,992 \\
\hline 10 & 0,998 & 0,994 \\
\hline
\end{tabular}

YSA metodunun eğitimi sonrası, numunelerin dielektrik parametrelerinin frekansa bağl1lıkları, YSA metoduyla elde edilmiştir. Deneysel sonuçlar ile YSA metodu ile elde edilen veriler karşılaştırma kolaylığının sağlanması amacıyla, Şekil 7 ve Şekil 8'de birlikte verilmiştir. İlgili grafiklerde siyah ile gösterilen semboller deneysel sonuçları, kırmızı ile gösterilen semboller ise YSA ile tahmin edilen sonuçları temsil etmektedir. 

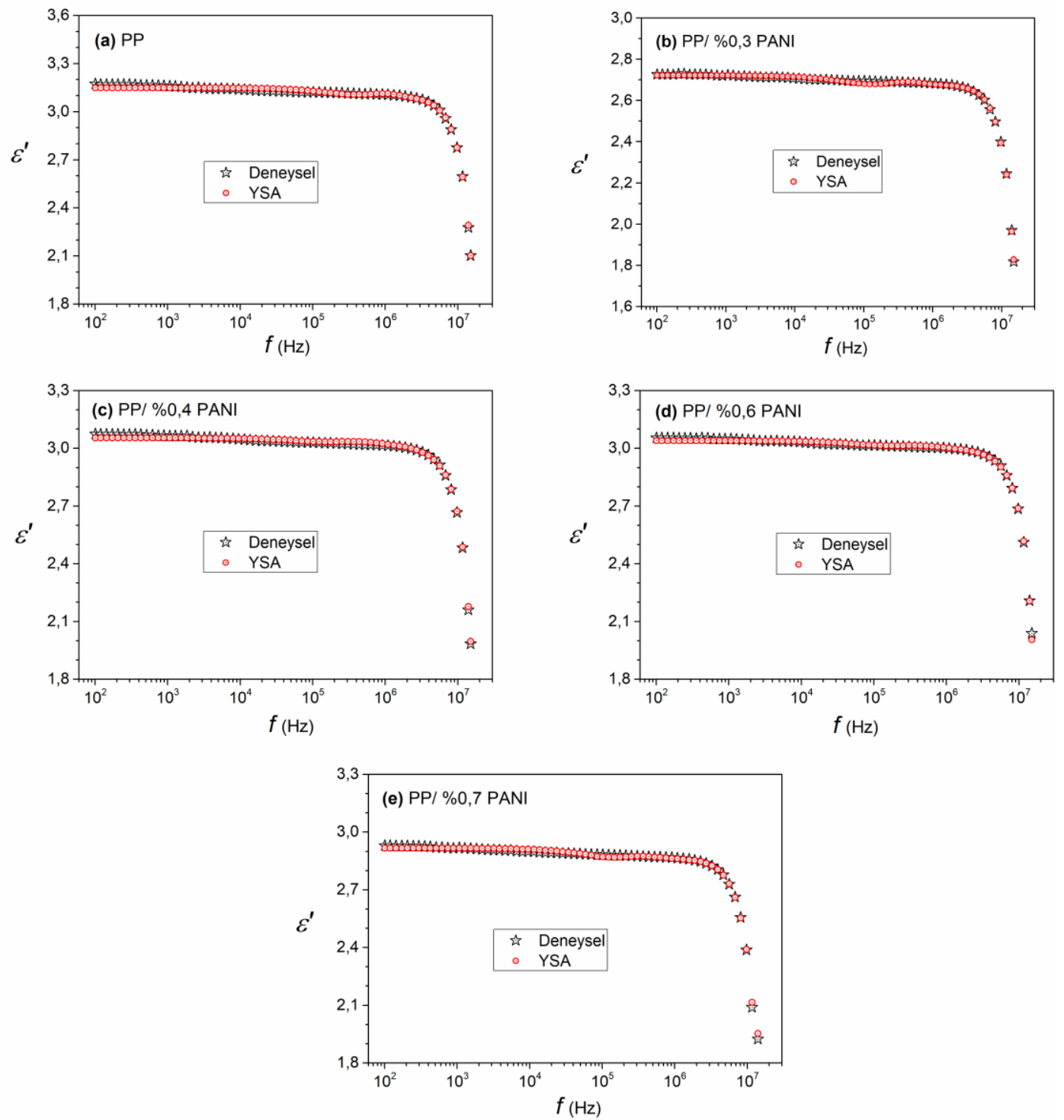

Şekil 7. Deneysel ve YSA ile tahmin edilmiş olan dielektrik fonksiyonun gerçek bileşen ( $\left.\varepsilon^{\prime}\right)$ değerlerinin karşılaştırılması. 

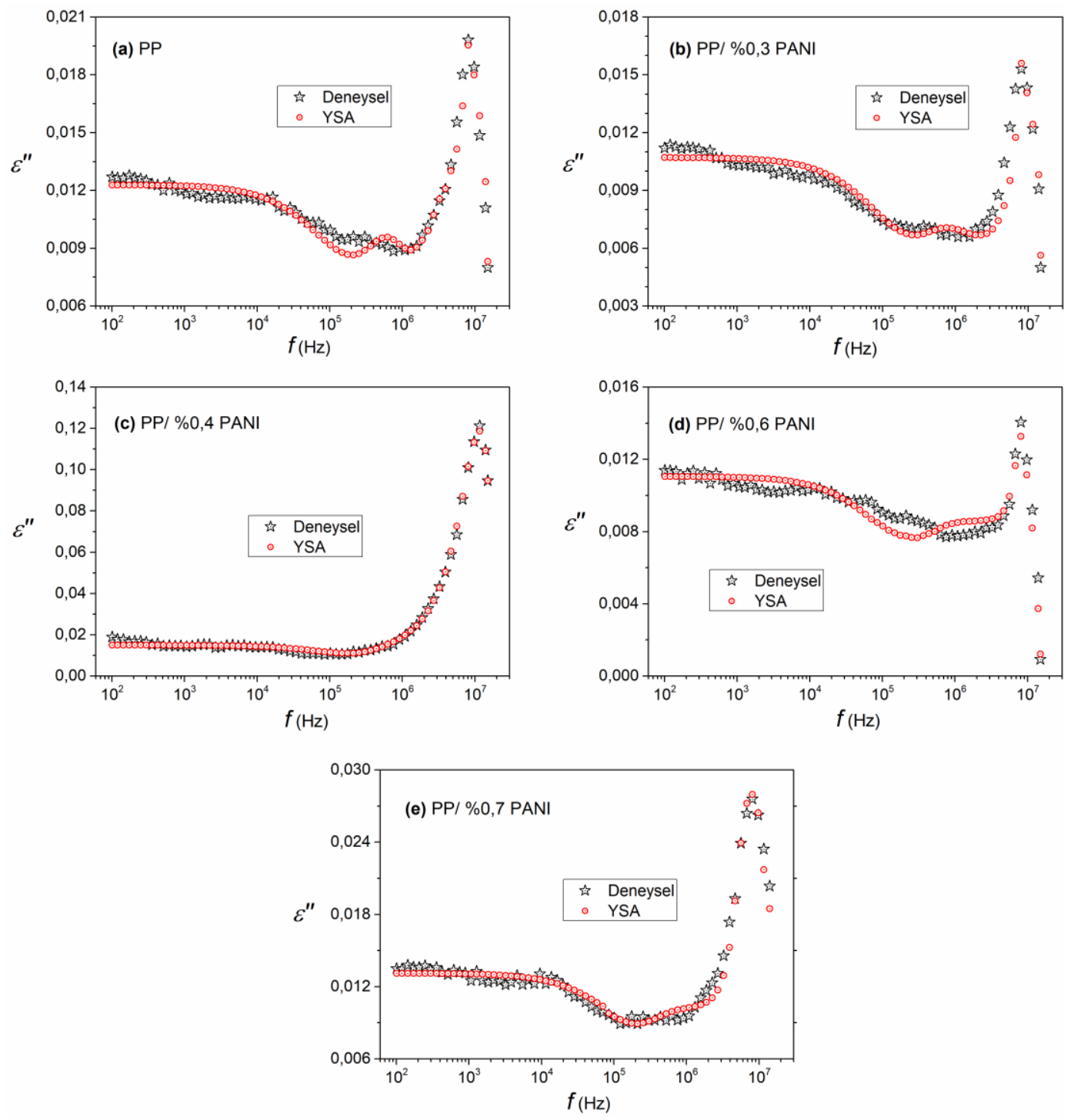

Şekil 8. Deneysel ve YSA ile tahmin edilmiş olan dielektrik fonksiyonun sanal bileşen ( $\left.\varepsilon^{\prime \prime}\right)$ değerlerinin karşılaş̧ırılması.

Şekil 7 ve 8'den de görüleceği üzere, tüm numuneler için hem dielektrik fonksiyonunun gerçek hem de sanal kısmı için frekansa bağl11ık, YSA metodu ile deneysel sonuçlarla yüksek bir uyumluluk içinde tespit edilmiştir. Ayrıca, $\varepsilon^{\prime}$ parametresinin yaklaşı $100 \mathrm{~Hz}-10 \mathrm{MHz}$ frekans aralığında neredeyse frekanstan bağımsız davranışı, YSA ile elde edilen verilerde de gözlenmiştir. YSA modelinin $\varepsilon^{\prime}$ ve $\varepsilon^{\prime \prime}$ parametrelerinin tayinindeki performansı ise deneysel (gerçek) değerlerle ile YSA tahmin değerlerinin karşılaştırılması ile değerlendirilmiştir. Dielektrik parametreler $\varepsilon^{\prime}$ ve $\varepsilon^{\prime \prime}$ için YSA metodunun performans değerlendirmeleri sırasıyla Şekil 9(a) ve (b)'deki tahmine karşı çizilen gerçek değer grafiklerinde verilmiştir. 

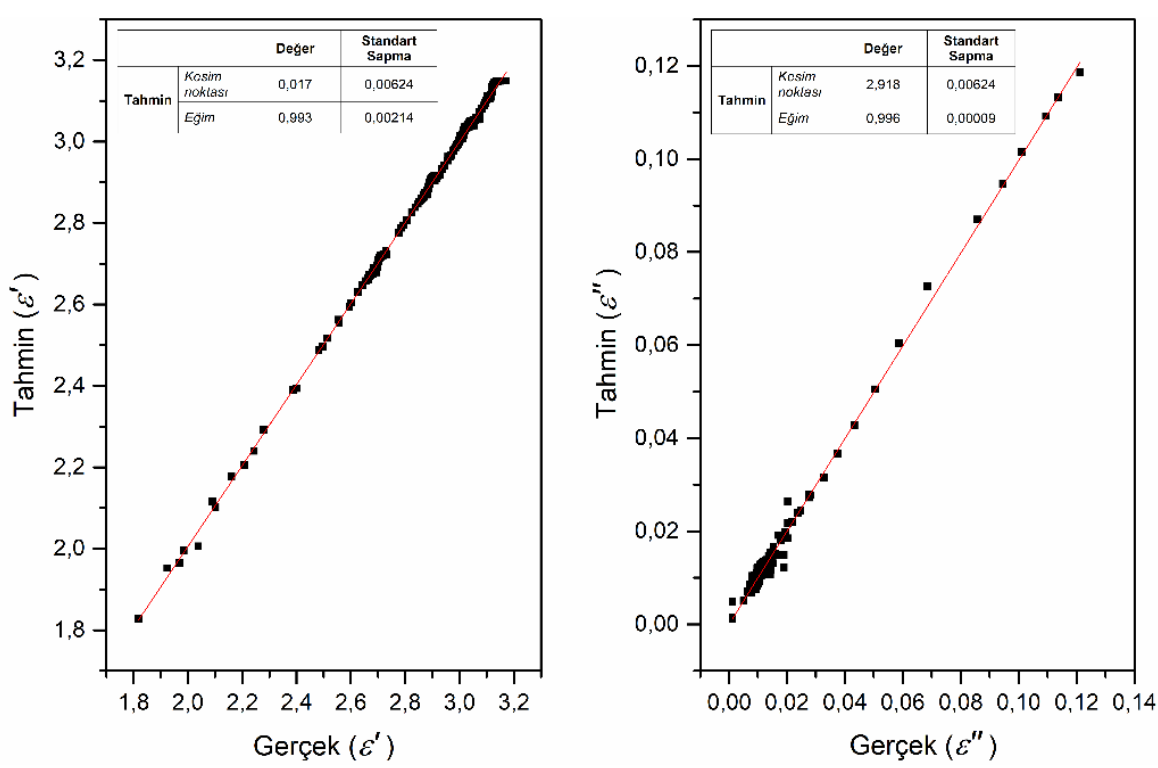

Şekil 9. Uygulanan YSA modelinin performans hesaplaması.

Şekil 9'daki grafiklere ek olarak, dielektrik parametrelere uygulanan YSA modelinin doğruluk performansının belirlenmesi amacıyla, belirleme katsayısı $(R)$ kare ortalama karekök hata ( RMSE )ve kare ortalama hata (MSE) değerleri Denklem (2.6), (2.7) ve (2.8) kullanılarak hesaplanmıştır. İlgili değerler Tablo 3'de verilmiştir. Gerek Şekil 9'daki grafikler gerekse de Tablo 2'deki değerlere istinaden, uygulanan YSA eğitim algoritmasının iyi çalıştığı ve $\varepsilon^{\prime}$ ile $\varepsilon^{\prime \prime}$ parametrelerinin, hem frekansa hem de PANI katkı konsantrasyonuna bağlı lineer olmayan ilişkisini öğrenebildiği sonucuna varılmıştır. Bu bağlamda, deneysel olarak hazırlanmamış kütlece farklı yüzdelerde PANI katkıları içeren PP/PANI kompozit malzemelerin $\varepsilon^{\prime}$ ve $\varepsilon^{\prime \prime}$ parametrelerinin hesaplanmasında YSA modelinin güvenilir bir metot olarak kullanılabileceği genel kanısına varılmıştır.

Tablo 3. YSA hesaplamalarının, belirleme katsayısı (R), kare ortalama karekök hata (RMSE) ve kare ortalama hata (MSE) de ğerleri

\begin{tabular}{|c|c|c|c|}
\hline Parametre & $\boldsymbol{R}$ & $\boldsymbol{R M S E}$ & $\boldsymbol{M S E}$ \\
\hline$\varepsilon^{\prime}$ & 0,993 & $8,8 \times 10^{-3}$ & $1,74 \times 10^{-6}$ \\
\hline$\varepsilon^{\prime \prime}$ & 0,992 & $1,1 \times 10^{-3}$ & $3,84 \times 10^{-7}$ \\
\hline
\end{tabular}

YSA modelinin dielektrik analizlere uygunluğunun anlaşılmasını takiben, bu çalışmada deneysel olarak hazırlanmamış kütlece farklı oranlarda PANI içeren bazı PP/PANI kompozitler için, frekansa bağlı olarak $\varepsilon^{\prime}$ ve $\varepsilon^{\prime \prime}$ parametrelerinin tahmini YSA modeli yardımıyla yapılmıştır. Bilindiği üzere, dielektrik parametrelere ait deneysel veriler saf PP, ile kütlece \% 0,3, \% $0,4 \% 0,6$ ve \% 0,7 PANI katkılı PP kompozitlere aitti. Başarı ile oluşturulmuş olan YSA modeli kullanılarak, katkı yüzdesi açısından hem interpolasyon bölgesinden ( $\% 0,1, \% 0,2$ ve \% 0,5$)$ hem de ekstrapolasyon bölgesinden $(\% 0,8$ ve $\% 1,0)$ farklı PANI katkı değerleri için $\varepsilon^{\prime}$ ve $\varepsilon^{\prime \prime}$ parametrelerinin frekansa bağlı değerleri hesaplanmıştır. Şekil 10 'da $\varepsilon^{\prime}$ ve $\varepsilon^{\prime \prime}$ parametrelerinin frekansa bağlılıkları, YSA metodu ile deneysel olarak hazırlanmamış numuneler için verilmiştir. Şekil 10(a)'dan PANI katkısının artışıyla, statik dielektrik sabitinin önce azaldığı, sonra arttığı ve son olarak tekrar azaldığı gözlenmiştir. Benzer şekilde, relaksasyon frekansı da artan PANI katkısıyla birlikte önce yüksek daha sonra düşük ve son olarak yüksek frekanslara kaymıştır. 



Şekil 10. Oluşturulan YSA modeli ile değerlerinin tahmini.

Artan PANI katkısıyla, $\varepsilon^{\prime}$ için daha önce deneysel verilerde tespit edilen genel eğilimi, YSA metoduyla da farklı PANI katkılı numuneler için de elde edilmiştir. Deneysel olarak gözlenen lineer olmayan bu davranışların, YSA metoduyla da benzer şekilde elde edildiği, Şekil 11'de sabit bir frekans için katk1 düzeyine karşılık çizdirilen statik dielektrik sabiti grafiğinden görülmektedir.

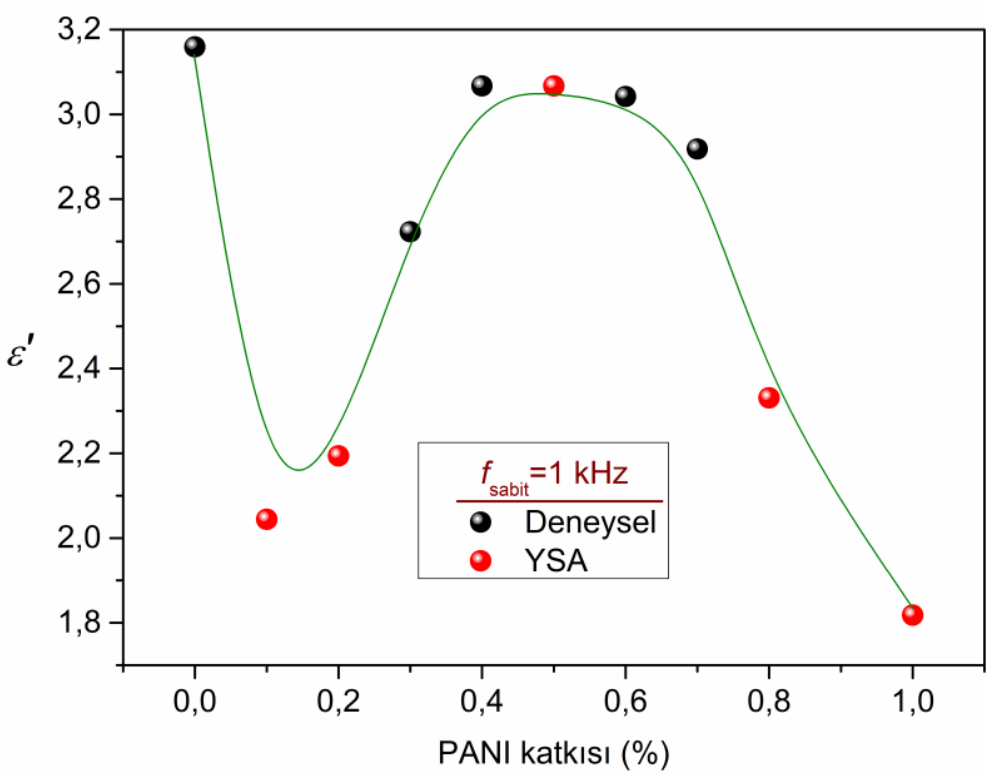

Şekil 11. 1 kHz sabit frekansında statik dielektrik sabitinin PANI katkı yüzdesi ile değişimi.

İlgili grafikte dielektrik fonksiyonun gerçek bileşenin PANI katkısıyla değişimi sabit $1 \mathrm{kHz}$ frekansında değerlendirilmiştir. Gerek interpolasyon gerekse de ekstrapolasyon bölgesinden seçilen katkı düzeyleri için yapılan YSA tahminleri, deneysel olarak gözlenen artan PANI katkısıyla dielektrik fonksiyonun gerçek bileşenin değişimine büyük oranda uyumludur.

\section{SONUÇ BÖLÜMÜ (CONCLUSION)}

Bu çalışmada, farklı PANI katkı konsantrasyonlu PP/PANI kompozitlerinin $\varepsilon^{\prime}$ ve $\varepsilon^{\prime \prime}$ parametrelerinin frekansa bağlı olarak değişimlerini tahmin etmek için bir YSA modeli oluşturulmuştur. Dielektrik 
parametreler açısından PANI katkısı arttıkça PP'nin lineer olmayan cevabına istinaden, YSA modeli kullanılmıştır. Modelin oluşturulmasında kullanılan eğitim veri seti, dielektrik ölçümlerden elde edilmiştir. Öncelikle YSA modelinin geçerlilik ve performans kriterleri belirlenerek; ilgili modelin bu parametreleri hesaplamakta uygun bir model olduğu tespit edilmiştir. YSA yöntemi ile yapılan test tahminlerinde \%99'luk doğruluk oranı elde edilmiştir. Bu tespiti takiben, önerilen YSA modeli kullanılarak daha önce deneysel olarak hazırlanmamış ve herhangi bir dielektrik ölçüm alınmamış farklı PP/PANI kompozitlerin, frekansa bağlı $\varepsilon^{\prime}$ ve $\varepsilon^{\prime \prime}$ parametreleri hesaplanmıştır. Böylece, YSA modellemesi sayesinde, kondansatör ve elektriksel yalıtkan için dielektrik malzeme üretimine yönelik olarak uygun konsantrasyonda PP ve PANI içeren kompozit önerisi yapılabilir. Ayrıca, bu çalışmada laboratuvarda deneysel olarak üretilen PP/PANI kompozitlerin empedans analizör yardımıyla kompleks dielektrik fonksiyonunun gerçek ve sanal bileşenlerini ölçmek yerine, artık bu tür polimer/polimer kompozitlerin dielektrik özelliklerini tahmin etmek için bilinen deneysel verilerle yapay sinir ağlarının kullanılabileceği ispat edilmiştir. Bununla birlikte, bu araştırma sonuçlarından yola çıkılarak YSA metodu kimya, metalürji, mineraloji ve meteoroloji gibi bilimin başka branşlarındaki parametrelerin tahmini için de örnek teşkil edebilir.

\section{KAYNAKLAR (REFERENCES)}

[1] A. Akinci, Mechanical and structural properties of polypropylene composites filled with graphite flakes. Archives of Materials Science and Engineering, 35: 2 (2009) 91-94.

[2] S. Nagasawa, A. Fujimori, T. Masuko, M. Iguchi, Crystallization of polypropylene containing nucleators. Polymer, 46: 14 (2005) 5241-5250.

[3] M. Chipara, D. Hui, P.V. Notingher, M.D. Chipara, K.T. Lau, J. Sankar and D. Panaitescu. On polyethylene-polyaniline composites. Composites Part B: Engineering, 34: 7 (2003) 637-645.

[4] M. Ates, A review study of (bio) sensor systems based on conducting polymers. Materials Science and Engineering: C, 33: 4 (2013) 1853-1859.

[5] H. Tang, Y. Ding, C. Zang, J. Gu, Q. Shen, J. Kan, Effect of Temperature on Electrochemical Degradation of Polyaniline. International Journal of Electrochemical Science, 9 (2014) 7239-7252.

[6] Zh. A. Boeva, V. G. Sergeyev, Polyaniline: Synthesis, Properties, and Application. Polymer Science Series C, 56: 1 (2014) 144-153.

[7] A. B. Samui, A. S, Patankar, J, Rangarajan and P. C. Deb, Study of polyaniline containing paint for corrosion prevention. Progress in Organic Coatings, 47: 1 (2003) 1-7.

[8] A. Mekki, B. Mettai, Z. Ihdene, R.Mahmoud, Z. Mekhalif. Inverse gas chromatography characterization of polyaniline complexes: application to volatile organic compounds sensing. Iranian Polymer Journal, 22: 9 (2013) 677-687.

[9] W. Z. Zhang, X. W. Kan, S. F. Jiao, J. G. Sun, D. S. Yang, B. Fang, Electrochemical characteristics and catalytic activity of polyaniline doped with ferrocene perchlorate. Journal of Applied Polymer Science, 102: 6 (2006) 5633-5639.

[10] E. Akbarinezhad, M. Ebrahimia, F. Sharif, M.M. Attar, H.R. Faridi, Synthesis and evaluating corrosion protection effects of emeraldine base PAni/clay nanocomposite as a barrier pigment in zinc-rich ethyl silicate primer, Progress in Organic Coatings 70: 1 (2011) 39-44

[11] M. Chipara, D. Hui, P. V. Notingher, M. D. Chipara, K. T. Lau, J. Sankar and D. Panaitescu, On polyethylene-polyaniline composites. Composites Part B: Engineering, 34: 7 (2003) 637-645. 
[12] P. Sukitpaneenit, T. Thanpitcha, A. Sirivat, C. Weder, R. Rujiravanit, Electrical Conductivity and Mechanical Properties of Polyaniline/Natural Rubber Composite Fibers. Journal of Applied Polymer Science, 106: 6 (2007) 4038-4046

[13] S. Chandran A. and S. K. Narayanankutty, Polyaniline-Coated Short Nylon Fiber/Natural Rubber Conducting Composite. Polymer-Plastics Technology and Engineering, 50: 5 (2011) 443-452

[14] M. J. da Silva, A. O. Sanches, L. F. Malmonge, J. A. Malmonge, Electrical, mechanical, and thermal analysis of natural Rubber/Polyaniline-Dbsa composite. Materials Research, 17: 1 (2014) 59-63.

[15] O. Eyecioglu, M. Kilic, Y. Karabul, U. Alkan, O. Icelli, Artificial Neural Networks Study on Prediction of Dielectric Permittivity of Basalt/PANI Composites, International Journal of Engineering Technologies, 2: 2 (2016) 42-48.

[16] S. Thawornwong, D. Enke, The adaptive selection of financial and economic variables for use with artificial neural networks. Neurocomputing, 56 (2004) 205-231.

[17] J. A. Jargon, K. C. Gupta, D. C. DeGroot, Applications of Artificial Neural Networks to RF and Microwave Measurements. Int. J. RF and Microwave CAE, 12 (2002) 3-24.

[18] M. Demetgül, Pnömatik Sistemde Gerçek Zamanlı Lvq Yapay Sinir Ağı Algoritması ile Arıza Tespiti. Pamukkale Üniversitesi Mühendislik Bilimleri Dergisi, 14: 1 (2008) 83-90.

[19] A. Habibi-Yangjeh, Prediction dielectric constant of different ternary liquid mixtures at various temperatures and compositions using artificial neural networks. Physics and Chemistry of Liquids, 45: 4 (2007) 471-478.

[20] T. Masters, Practical Neural Network Recipes in C++, California: Academic Press, 1993.

[21] I. A. Basheer, M. Hajmeer, Artificial neural networks: fundamentals, computing, design, and application. Journal of Microbiological Methods, 43 (2000) 3-31.

[22] Q. J.Zhang, K. C. Gupta, V. K. Devabhakuni, Artificial neural networks for RF and microwave design from theory to practice. IEEE Transactions on Microwave Theory and Techniques, 51: 4 (2003) 1339-1350.

[23] M. İnal ve F. Aras, Yalıtkan malzemelerin dielektrik özelliklerinin yapay sinir ağlarıyla belirlenmesi. Gazi Üniv. Müh. Mim. Fak. Der., 20: 4 (2005) 455-462.

[24] R. C. Schweitzer, J. B. Morris, The development of a quantitative structure property relationship (QSPR) for the prediction of dielectric constants using neural networks. Analytica Chimica Acta, 384 (1999) 285-303.

[25] A. Habibi-Yangjeh, Prediction dielectric constant of different ternary liquid mixturesat various temperatures and compositions using artificialneural networks. Physics and Chemistry of Liquids, 45: 4 (2007) 471-478.

[26] D. J. Scott, P. V. Coveney, J. A. Kilner, J. C. H. Rossiny, N. Mc N. Alford, Prediction of the functional properties of ceramic materials from composition using artificial neural networks. Journal of the European Ceramic Society, 27 (2007) 4425-4435.

[27] A. Jurado, D. Escot, D. Poyatos, I. Montiel, Application of artificial neural networks to complex dielectric constant estimation from free-space measurements. In: J. Mira, J. M. Ferrandez, J. R Alvarez, F. de la Paz, F. J. Toledo (eds) Methods and models in artificial and natural computation. A homage to Professor Mira's scientific legacy. IWINAC 2009. Lecture Notes in Computer Science, 5601, Berlin: Springer, 2009. 
[28] V. F. Lvovich, Impedance Spectroscopy Applications to Electrochemical and Dielectric Phenomena, New Jersey: Wiley, 2012.

[29] M. T. Hagan, M. B. Menhaj, Training feedforward networks with the Marquardt algorithm. IEEE Transactions on Neural Networks, 5: 6 (1994) 989-993.

[30] D. Svozil, V. Kvasnicka, J. Pospichal, Introduction to multi-layer feed-forward neural networks," Chemometrics and Intelligent Laboratory Systems, 39: 1, (1997) 43-62.

[31] R. Hecht-Nielsen, Theory of the backpropagation neural network. Neural Networks for Perception, (1992) 65-93.

[32] S.Sapna, A. Tamilarasi, M. P. Kumar, Backpropagation Learning Algorithm Based on Levenberg Marquardt Algorithm. Computer Science \& Information Technology 7 (2012) 393-398.

[33] K. Levenberg, A Method for the Solution of Certain Non-Linear Problems in Least Squares. Quarterly of Applied Mathematics, 2: 1 (1944) 164-168.

[34] D. Marquardt, An Algorithm for Least-Squares Estimation of Nonlinear Parameters, SIAM Journal on Applied Mathematics, 11: 1 (1963) 431-441.

[35] A. A. Suratgar, M. B. Tavakoli, A. Hoseinabadi, Modified Levenberg-Marquardt Method for Neural Networks Training, World Academy of Science, Engineering and Technology, 1: 6 (2007) 17451747.

[36] P. K. C. Pillai, G. K. Narula, A. K. Tripathi, Dielectric properties of Polypropylene/Polycarbonate Polyblends, Polymer Journal, 16: 7 (1984) 575-578.

[37] Y. Dang, Y. Wang, Y. Deng, M. Li, Y. Zhang, Zhi-Wei Zhang, Enhanced dielectric properties of polypropylene based composite using $\mathrm{Bi}_{2} \mathrm{~S}_{3}$ nanorod filler, Progress in Natural Science: Materials International, 21: 3 (2011) 216-220. 